\title{
Article \\ Direct Metal-Free Transformation of Alkynes to Nitriles: Computational Evidence for the Precise Reaction Mechanism
}

\author{
Lucija Hok (1) and Robert Vianello *(1) \\ Division of Organic Chemistry and Biochemistry, Ruđer Bošković Institute, Bijenička Cesta 54, 10000 Zagreb, \\ Croatia; lucija.hok@irb.hr \\ * Correspondence: robert.vianello@irb.hr
}

check for

updates

Citation: Hok, L.; Vianello, R. Direct Metal-Free Transformation of Alkynes to Nitriles: Computational Evidence for the Precise Reaction Mechanism. Int. J. Mol. Sci. 2021, 22, 3193. https://doi.org/10.3390/ ijms22063193

Academic Editor: Oleg V. Mikhailov

Received: 29 January 2021

Accepted: 19 March 2021

Published: 21 March 2021

Publisher's Note: MDPI stays neutral with regard to jurisdictional claims in published maps and institutional affiliations.

Copyright: (c) 2021 by the authors. Licensee MDPI, Basel, Switzerland. This article is an open access article distributed under the terms and conditions of the Creative Commons Attribution (CC BY) license (https:/ / creativecommons.org/licenses/by/ $4.0 /)$.

\begin{abstract}
Density functional theory calculations elucidated the precise reaction mechanism for the conversion of diphenylacetylenes into benzonitriles involving the cleavage of the triple $\mathrm{C} \equiv \mathrm{C}$ bond, with $\mathrm{N}$-iodosuccinimide (NIS) as an oxidant and trimethylsilyl azide $\left(\mathrm{TMSN}_{3}\right)$ as a nitrogen donor. The reaction requires six steps with the activation barrier $\Delta G^{\ddagger}=33.5 \mathrm{kcal} \mathrm{mol}^{-1}$ and a highly exergonic reaction free-energy $\Delta G_{R}=-191.9 \mathrm{kcal} \mathrm{mol}^{-1}$ in MeCN. Reaction profiles agree with several experimental observations, offering evidence for the formation of molecular $\mathrm{I}_{2}$, interpreting the necessity to increase the temperature to finalize the reaction, and revealing thermodynamic aspects allowing higher yields for alkynes with para-electron-donating groups. In addition, the proposed mechanism indicates usefulness of this concept for both internal and terminal alkynes, eliminates the option to replace NIS by its $\mathrm{Cl}$ - or Br-analogues, and strongly promotes $\mathrm{NaN}_{3}$ as an alternative to $\mathrm{TMSN}_{3}$. Lastly, our results advise increasing the solvent polarity as another route to advance this metal-free strategy towards more efficient processes.
\end{abstract}

Keywords: azides; DFT calculations; cyanides; $N$-iodosuccinimide; triple $\mathrm{C} \equiv \mathrm{C}$ bond cleavage

\section{Introduction}

The transformation of alkynes is a fundamental method that has been widely used in organic synthesis [1-5] to afford ketones [6,7], diketones [8,9], acids and their derivatives [10-12], alkyl or alkenyl halides [13,14], cycloalkanes or cycloalkenes [15-17], and nitriles [18-25], which makes these processes highly appealing in academic research and industrial applications [5]. Amongst many reactions of the $\mathrm{C} \equiv \mathrm{C}$ triple bond, its cleavage is deemed to be one of the most challenging targets and has stimulated new conceptual strategies in the organic community in recent years [5,10-12,15-25]. A triple bond having three shared electron pairs between two atoms is known as one of the strongest chemical bonds [4,5]. In spite of its large bond dissociation energy ( $>200 \mathrm{kcal} \mathrm{mol}^{-1}$ ), a complete cleavage of a $\mathrm{C} \equiv \mathrm{C}$ triple bond is common in general organic chemistry [26]. Different from conventional organic synthesis, this methodology enables the reorganization of molecular skeletons and leads to the collection of valuable structural units in a straightforward and atom-economic fashion by retrosynthetic disconnections [10]. Most such approaches rely on oxidative cleavage with stoichiometric organometallic reagents and oxidants [27], such as $\mathrm{Au}$ [15,28], Ag [21], Pd [29,30], Ru [31,32], Rh [33], and Cu [34] species. These methods are promising since alkynes are excellent transition metal ligands and their complexes exhibit a variety of reactivities. However, these methods suffer from harsh reaction conditions, restricted substrate scope, and multiple limitations, such as environmental unfriendliness, the use of costly and/or toxic catalysts, and possible transition-metal impurities, which underlines the need to develop metal-free routes to the $\mathrm{C} \equiv \mathrm{C}$ bond cleavage [23-25] that are currently rare. Recently, important progress was made by Yanada and co-workers [22], who reported the $N$-iodosuccinimide-mediated direct cleavage of internal alkynes to nitriles using trimethylsilyl azide $\left(\mathrm{TMSN}_{3}\right)$ as a nitrogen source (Scheme 1). 


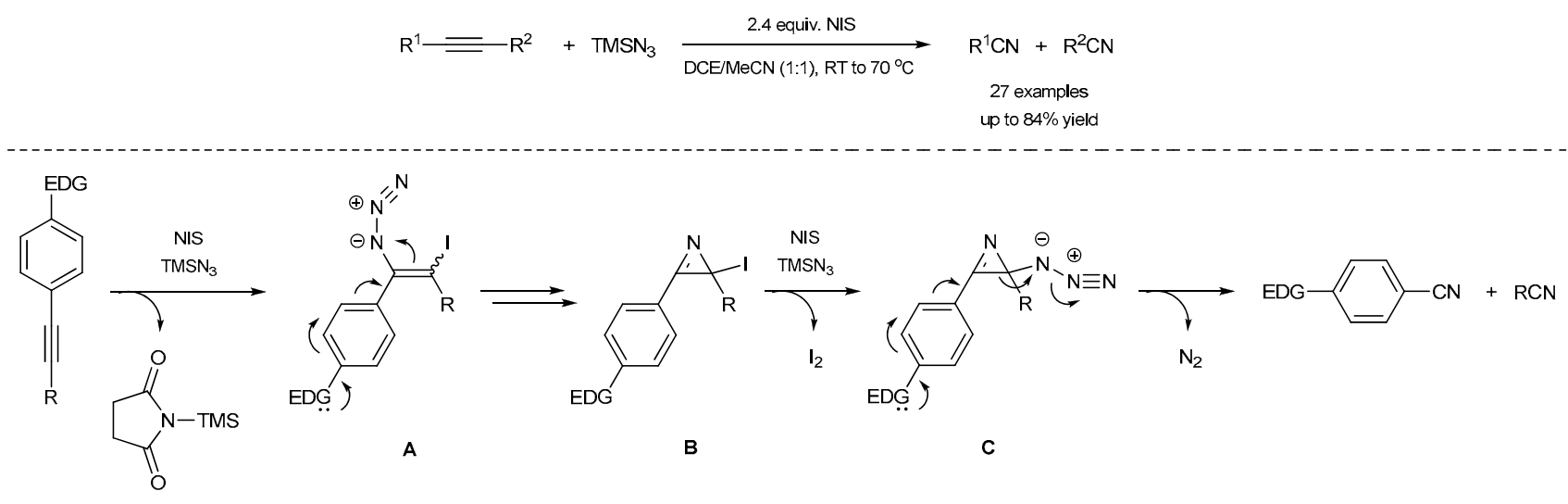

Scheme 1. Triple $\mathrm{C} \equiv \mathrm{C}$ bond cleavage reported by Yanada and co-workers [22] (top), and their proposed mechanism (bottom).

Nitriles are versatile building blocks and precursors in organic synthesis, as they can be easily transformed into aldehydes, amines, amides, thioamides, acids, esters, heterocyclic compounds, etc. [35-37]. The cyano group is ubiquitous in useful natural products, pharmaceuticals, top-selling drugs, agricultural chemicals, functional materials, and dyes [38-44]. Conventional methods to access nitriles, such as the Sandmeyer [45] and Rosenmund von Braun reactions [46,47], or transition-metal-mediated cyanation of aryl halides with a cyanide source [48-50], were widely employed in the early years. Although mostly quite efficient, these methods are generally not favored due to the use of toxic metals and the emission of hazardous HCN gas [51]. As mentioned, nitrogenation of alkynes with $\mathrm{TMSN}_{3}$, achieved by Yanada's group, does not employ cyanide salts and metal oxidants, which certainly promotes this sustainable route as a topic of considerable interest. Using 2.4 equivalents of NIS and TMSN ${ }_{3}$ in DCE:MeCN (1:1), starting at room temperature and rising to $70^{\circ} \mathrm{C}$, the authors explored the reactivity of an array of terminal and internal diaryl- and aryl-alkyl alkynes. In the case of symmetrical and unsymmetrical systems, the reaction proceeded quite satisfactorily, especially involving aryl moieties with an electron-donating group [22,51].

Inspired by these experimental advances, we used DFT calculations to clarify the precise mechanism of Yanada's reactions. The mechanistic pathway postulated by authors (Scheme 1) [22] relies on the formation of an unstable iodo vinyl azide as the keyintermediate $\mathrm{A}$, in which the electron-donating group (EDG) on the aryl ring can accelerate the formation of intermediate $B$, releasing $\mathrm{N}_{2}$ under thermal conditions, the latter proposed as the driving force of this process. Subsequent nucleophilic substitution of iodoazirine $\mathrm{B}$ with azide anion gives an intermediate $\mathrm{C}$, and finally a ring-opening reaction affords the matching nitriles. Despite the proposed mechanism, the conversion of the key-vinyl iodide derivatives into nitriles deserves further studies, in order to elucidate transition via iodo azirine derivatives and provide deeper insights into alkyne cleavage reactions. Our calculations show different mechanistic routes to those proposed by Yanada [22] and reveal a very modest electronic effect of the para-EDG substituents on the reaction outcomes while offering guidelines to advance this reaction strategy and design new catalytic reaction systems towards even more efficient transformations.

\section{Results and Discussion}

Chemical structures of studied systems with the relevant atom labeling used throughout the text are presented in Figure 1. 

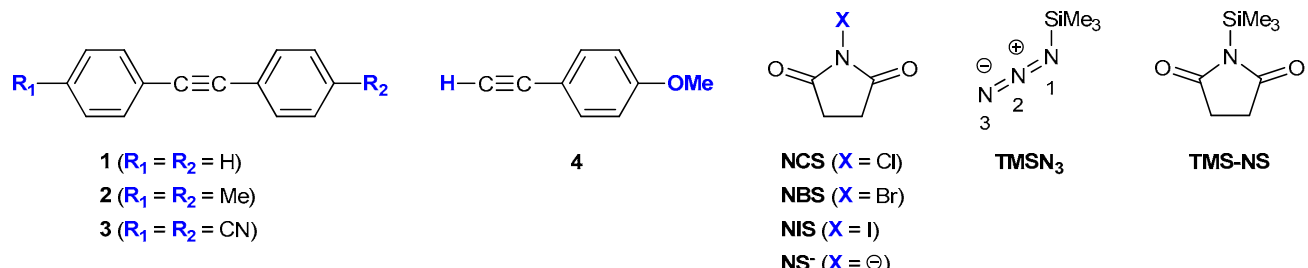

Figure 1. Chemical structures of investigated systems.

\subsection{The Uncatalyzed Reaction with $\mathrm{N}_{2}$ as a Nitrogen Source in Acetonitrile}

As mentioned, one of the dominant reasons for the low reactivity of alkynes is the high intrinsic bond dissociation energies of the $C \equiv C$ linkage, which often exceed $200 \mathrm{kcal} \mathrm{mol}^{-1}$ as opposed to those for the single $\mathrm{C}-\mathrm{C}$ bonds that are typically found below $100 \mathrm{kcal} \mathrm{mol}^{-1}$ [52]. Our data for the parent diphenylacetylene 1 reveal the bond dissociation energy of $180.7 \mathrm{kcal} \mathrm{mol}^{-1}$ in $\mathrm{MeCN}$, tying in with the preceding conclusion. Nevertheless, to further demonstrate the difficulty of cleaving the $C \equiv C$ bond and converting alkynes into the matching nitriles, we studied a potential uncatalyzed direct transformation of $\mathbf{1}$ into two benzonitriles using molecular $\mathrm{N}_{2}$ as a nitrogen source, as depicted in Scheme 2.

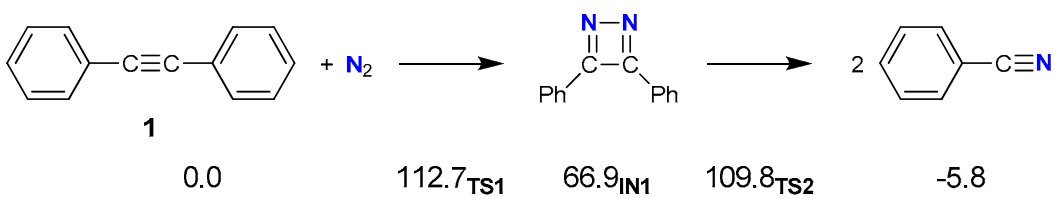

Scheme 2. Direct conversion of 1 into benzonitriles with $\mathrm{N}_{2}$. Relative Gibbs free energies (in $\mathrm{kcal} \mathrm{mol}^{-1}$ ) correspond to the MeCN solution. TS and IN denote transition states and intermediates.

Interestingly, the examined process is thermodynamically feasible with an exergonic reaction free energy $\Delta G_{R}=-5.8 \mathrm{kcal} \mathrm{mol}^{-1}$. However, the activation free energy is extremely high at $\Delta G^{\ddagger}=112.7 \mathrm{kcal} \mathrm{mol}^{-1}$ for the initial rate-limiting attachment of $\mathrm{N}_{2}$ onto the $\mathrm{C} \equiv \mathrm{C}$ bond, making this process highly unlikely even under elevated temperatures. The first transition state TS1 is not symmetrical, rather one of the $\mathrm{N}$-atoms from $\mathrm{N}_{2}$ attaches to alkyne carbon $\left(\mathrm{d}_{\mathrm{C}-\mathrm{N}}=1.42 \AA\right)$, while the other is further away from its vicinal partner $(2.35 \AA)$. All of this elongates the central C-C bond, from $1.21 \AA$ in $\mathbf{1}$ to $1.39 \AA$ in TS1, and then to $1.53 \AA$ in the IN1 intermediate. This makes the subsequent carbon-carbon cleavage slightly less demanding, and occurring over the transition state TS2, being $109.8 \mathrm{kcal}$ $\mathrm{mol}^{-1}$ higher than $\mathbf{1}$. The obtained profile ties in with recently underlined ideas about the unsymmetrical character of various cycloaddition reactions [53], and strongly emphasizes the need for the catalytic environment in order for this reaction concept to occur under normal conditions.

\subsection{Reaction on Diphenylacetylene with NIS and $\mathrm{TMSN}_{3}$ in Acetonitrile}

Diphenylacetylene $\mathbf{1}$ is a symmetrical molecule, making both of its alkyne C-atoms likely candidates to undergo nucleophilic or electrophilic reactivity, as well as underlying the possibility that both reactants, NIS and $\mathrm{TMSN}_{3}$, attack the triple bond either in a concerted or a stepwise fashion. Our calculations show that a stepwise activation of the triple bond in 1 by either reactant offers no stable intermediates. In other words, the scan of the $\mathrm{N}-\mathrm{I} \cdots \mathrm{C}_{\text {alkyne }}(\mathbf{1})$ coordinate with NIS, or either of the $\mathrm{Si}-\mathrm{N} 1 \cdots \mathrm{C}_{\text {alkyne }}(\mathbf{1})$ or $\mathrm{Si}-\mathrm{N}=\mathrm{N}=\mathrm{N} 3 \cdots \mathrm{C}_{\text {alkyne }}(\mathbf{1})$ coordinates with $\mathrm{TMSN}_{3}$, proceeds uphill in energy with no indications of any transition states or formed products. We also considered two additional possibilities for the initial $\mathrm{TMSN}_{3}$ approach, namely a simultaneous attack of (i) Si and $\mathrm{N} 1$ atoms, or (ii) N1 and N3 atoms onto the $\mathrm{C} \equiv \mathrm{C}$ bond. The first attempt gave the four membered $\mathrm{C} \equiv \mathrm{C}-\mathrm{N} 1-\mathrm{Si}$ ring, yet with a very high activation barrier $\Delta G^{\ddagger}=50.1 \mathrm{kcal} \mathrm{mol}^{-1}$, 
while the second one, in line with a proposed such 1,3-cycloaddition reactivity of $\mathrm{HN}_{3}$ onto the alkene bond [21], produced a triazole through a one-step process [53], having the N1-attached $\mathrm{SiMe}_{3}$ group, and a much lower activation barrier $\Delta G^{\ddagger}=30.4 \mathrm{kcal} \mathrm{mol}^{-1}$. Nevertheless, the former intermediate is very stable $\left(-71.1 \mathrm{kcal} \mathrm{mol}^{-1}\right)$, with no tendency to easily lose the $-\mathrm{SiMe}_{3}$ group, thus hindering any further reaction progress, either (i) through a direct cleavage of the $\mathrm{N}-\mathrm{Si}$ bond, being uphill in energy and raising the overall activation energy to $\Delta G^{\ddagger}=53.6 \mathrm{kcal} \mathrm{mol}^{-1}$, or (ii) by the approach of NIS (even its more nucleophilic $\mathrm{I}^{-}$anion) towards it, which, in both cases, gave no stable products. All of these led us to rule out the possibility for a stepwise initiation of the $C \equiv C$ bond cleavage.

A one-step approach of NIS and $\mathrm{TMSN}_{3}$ onto the $\mathrm{C} \equiv \mathrm{C}$ bond in $\mathbf{1}$ resulted as a likely mechanism to initiate the reaction. From the perspective of $\mathrm{TMSN}_{3}$, this can occur with either its N1 or terminal N3 atoms (Figure 1), with the latter being more demanding with a higher activation energy $\Delta G^{\ddagger}=36.1 \mathrm{kcal} \mathrm{mol}^{-1}$. This is reasonable given the lower N3-nucleophilicity, as seen in its atomic charge of $-0.14 \mathrm{le} \mid$ in the isolated $\mathrm{TMSN}_{3}$, as opposed to a much higher charge of -0.74 I e I on N1, being in line with many reports on the reactivity of this system [54-57]. As such, a much more feasible route occurs if $\mathrm{TMSN}_{3}$ approaches 1 with its N1 atom (Figure 2), offering the first transition state TS1, being $26.8 \mathrm{kcal} \mathrm{mol}^{-1}$ higher than reactants $\mathrm{R}$. There, $\mathrm{TMSN}_{3}$ acts as a nucleophile, given the mentioned charge on its $\mathrm{N} 1$ atom of $-0.74 \mathrm{Ie} \mid$ and within the azide unit of -0.61 |e $\mid$ in R, to assume -0.66 and -0.32 |e $\mid$ in the transition state TS1, respectively. In contrast, NIS participates as an electrophile, seen in the charge on the iodine atom being changed from $0.42 \mathrm{le} \mid$ in reactants to $0.31 \mathrm{le} \mid \mathrm{in}$ TS1. All of this reduces the bond order of the central $\mathrm{C} \equiv \mathrm{C}$ linkage and elongates it from 1.21 to $1.29 \AA$, in the same order. The latter is accompanied by the bending of the $C_{\text {phenyl }}-C \equiv C$ angles, from linearity in $R$ to values of 131.3 and $141.9^{\circ}$ in TS1, where, accordingly, the charge on the alkyne C-atom to accommodate the nucleophilic azide is $0.16 \mathrm{I} \mid \mathrm{l}$, while on its vicinal counterpart, to accept the electrophilic $\mathrm{I}^{+}$cation, it is $-0.24|\mathrm{e}|$, thus firmly supporting previous conclusions.
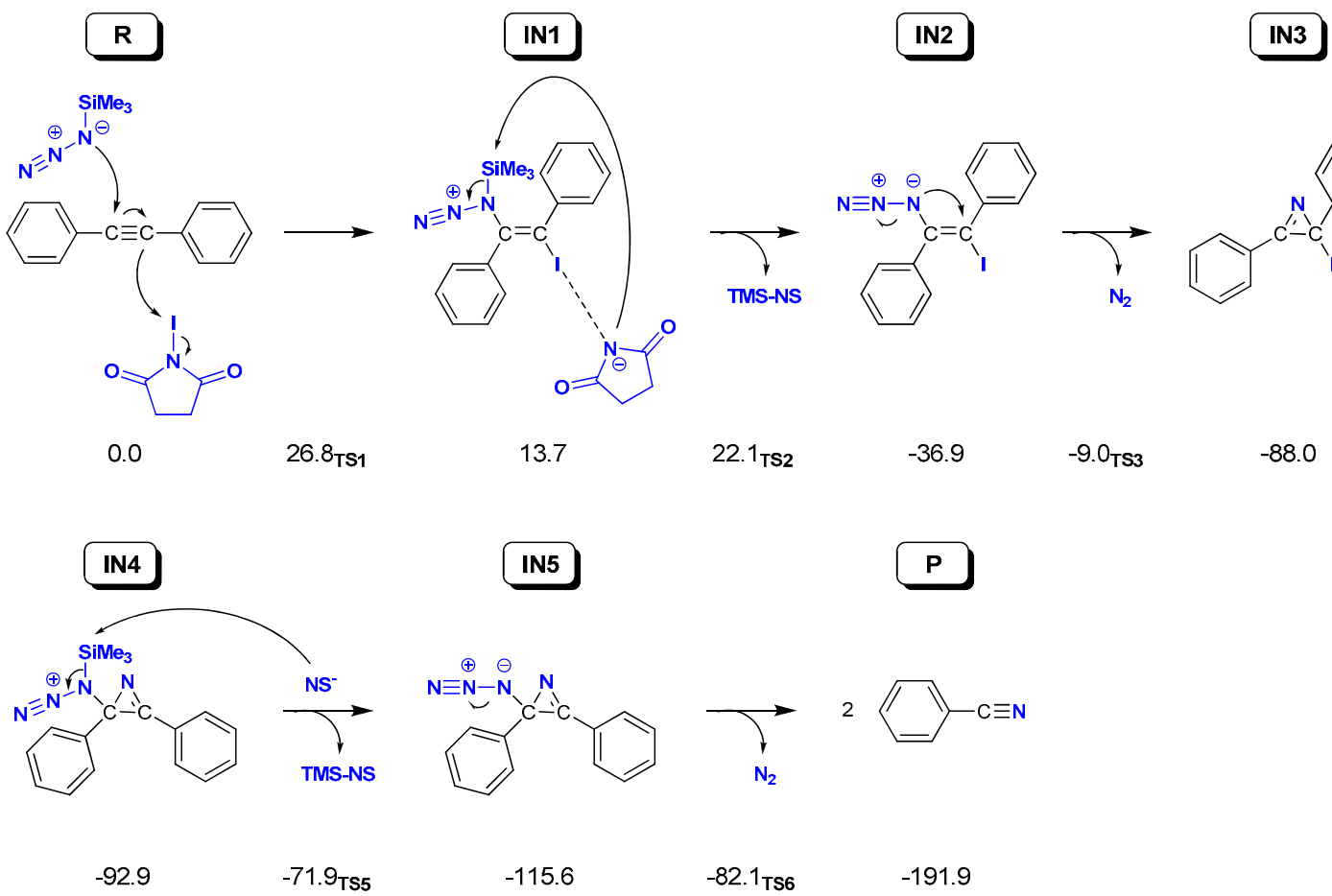

Figure 2. Reaction mechanism for the conversion of diphenylacetylene $\mathbf{1}$ to benzonitrile with $N$-iodosuccinimide (NIS) as an oxidant and trimethylsilyl azide $\left(\mathrm{TMSN}_{3}\right.$ ) as a nitrogen source. Relative Gibbs free energies (in kcal mol ${ }^{-1}$ ) $\mathrm{correspond} \mathrm{to}^{-}$ the MeCN solution. TS and IN denote transition states and intermediates, while R and P stand for reactants and products. Graphical representation of the reaction profile is given as Figure S1. 
The initial step is endergonic $\left(\Delta G_{R}=13.7 \mathrm{kcal} \mathrm{mol}^{-1}\right)$, giving a high-energy alkene intermediate IN1, most favorably as the $E$-isomer (Figure 2). An alternative approach of NIS and TMSN 3 that would give the matching Z-isomer is sterically hindered and linked with a $4.9 \mathrm{kcal} \mathrm{mol}^{-1}$ higher barrier, thus is disfavored and not considered further. However, it is worth mentioning that such a kinetic difference still allows for the formation of the corresponding Z-isomer, but at significantly lower yields and around 3-4 orders of magnitude slower rates, thus placing our results in qualitative agreement with Yanada and co-workers [22], who reported the isolation of a mixture of $E$ - and Z-stereoisomers in around $2: 1$ ratio. The relative instability of IN1 has a dominant contribution in the fact that the azide moiety still bears the attached $-\mathrm{SiMe}_{3}$ group, with the $\mathrm{Si}-\mathrm{N}$ distance being not much changed from $1.78 \AA$ in $\mathrm{TMSN}_{3}$ into $1.88 \AA$ in IN1. Additionally, the formed succinimide anion NS ${ }^{-}$is still partially bonded to iodine in IN1 $\left(\mathrm{d}_{\mathrm{N}-\mathrm{I}}\right.$ is $2.06 \AA$ in $\mathrm{R}, 2.20 \AA$ in TS1, and $2.36 \AA$ in IN1). While its exclusion from IN1 would be favorable $\left(\Delta G_{R}=-12.5 \mathrm{kcal} \mathrm{mol}^{-1}\right)$, in the next step, $\mathrm{NS}^{-}$approaches the Si-atom and cleaves the $\mathrm{Si}-\mathrm{N}$ bond within $\mathrm{TMSN}_{3}$. This nucleophilic attack is supported by the positive charge on the Si-atom of 1.91 le I in IN1, being further increased from $1.86 \mathrm{lel}$ in the isolated $\mathrm{TMSN}_{3}$, thus facilitating the reaction. The latter requires only $8.4 \mathrm{kcal} \mathrm{mol}^{-1}$ to reach the second transition state TS2 describing the cleavage of the mentioned $\mathrm{Si}-\mathrm{N}$ bond in $\mathrm{TMSN}_{3}$ and the formation of a new $\mathrm{Si}-\mathrm{N}$ bond with $\mathrm{NS}^{-}$to offer TMS-NS as a byproduct (Figure 2). Departure of the latter is favored $\left(-11.6 \mathrm{kcal} \mathrm{mol}^{-1}\right)$, contributing to the total reaction free energy for the formation of intermediate IN2 of $\Delta G_{R}=-36.9 \mathrm{kcal} \mathrm{mol}^{-1}$, thus overcoming the potential earlier exclusion of $\mathrm{NS}^{-}$from IN1 and allowing the reaction to proceed to this point. IN2 features azide and iodine attached as E-moieties to the rest of the 1,2-diphenylvinyl skeleton, although significantly twisted, with a torsional angle between phenyl rings of $47.5^{\circ}$, imposed to reduce steric interference among substituents. In addition, the central CC linkage assumes a typical alkene double bond distance of $1.35 \AA$, with the attached azide and iodine at the matching C-N and C-I distances of 1.43 and $2.31 \AA$, respectively. Once IN2 is afforded, its azide undergoes an internal cyclization, where the $\mathrm{N}$-atom directly bonded to carbon approaches the neighboring alkene $\mathrm{C}$-atom to give an even more stable 2-iodo- $\mathrm{H}$ azirine intermediate IN3, gaining further $45.4 \mathrm{kcal} \mathrm{mol}^{-1}$ in the reaction free energy from IN2, and additional $5.7 \mathrm{kcal} \mathrm{mol}^{-1}$ for the exclusion of the formed $\mathrm{N}_{2}$, all despite featuring a highly strained three-membered azirine ring. This suggests this step is promoted by the cleavage of the azide $\mathrm{N}-\mathrm{N}$ bond and the departure of the stable $\mathrm{N}_{2}$ (Figure 2), with the relevant azide N1-N2 bond already increased from $1.13 \AA$ in IN2 to $1.72 \AA$ in TS3. Still, the accompanying activation free energy is enhanced to $\Delta G^{\ddagger}=27.9 \mathrm{kcal} \mathrm{mol}^{-1}$, being the highest up until now, which, together with the high exergonicity of the IN3 formation, helps explain two different experimental observations [22]: (i) the fact that the authors isolated the intermediate IN2 in a 39\% yield following the reaction at room temperature for $3 \mathrm{~h}$, and (ii) an accelerated formation of IN3 accompanied by the release of $\mathrm{N}_{2}$ gas only after increasing the reaction temperature to $70^{\circ} \mathrm{C}$ for $5 \mathrm{~h}$, which are both strongly confirmed by the calculated reaction profile.

The next sequence converts the 2-iodo-2 $\mathrm{H}$-azirine intermediate IN3 into its 2-azide analogue IN5, which our calculations show is a necessary precondition that affords two nitriles (Figure 2). In other words, the iodine in IN3 should be replaced by the azide $\mathrm{N}_{3}{ }^{-}$to complete the alkyne-to-nitrile conversion. However, IN3 is not prone to a simple substitution, which differs from the proposal by Yanada (Scheme 1), as all of our attempts to model such a process gave no suitable transition states or intermediates, typically resulting in the breaking of the strained azirine ring. In doing so, we considered both the SN1 reaction possibility, which did not provide a favorable cleavage of the C-I bond in IN3, and the $\mathrm{SN} 2$ reaction alternative with either $\mathrm{TMSN}_{3}$ or its even more nucleophilic azide $\mathrm{N}_{3}{ }^{-}$anion, which all failed, as well as their 1,3-cycloaddition on the unsaturated $\mathrm{N}=\mathrm{C}$ bond [21]. Another route to introduce azide in IN3 is the addition reaction of $\mathrm{TMSN}_{3}$ on the unsaturated azirine $\mathrm{C}$-atom. This is justified by a notably positive charge on this $\mathrm{C}$-atom in IN3 of 0.32 le $\mid$, while, for example, the vicinal double-bonded $\mathrm{N}$-atom is largely 
negative at -0.38 | e I. The addition of $\mathrm{TMSN}_{3}$ can occur either (i) on its own, or (ii) in a concerted fashion with additional NIS, thus mimicking a case during the initial $\mathrm{R} \rightarrow \mathrm{IN} 1$ conversion. The latter one-step approach requires $16.3 \mathrm{kcal} \mathrm{mol}^{-1}$ to form a reactive complex with IN3 and further $21.0 \mathrm{kcal} \mathrm{mol}^{-1}$ to reach the transition state describing a simultaneous cleavage of the $\mathrm{C}-\mathrm{I}$ bond and the formation of a new $\mathrm{C}-\mathrm{N}$ bond with $\mathrm{TMSN}_{3}$. This gives the cleaved $\mathrm{I}^{-}$anion, which is captured by the nearby NIS to afford the molecular $\mathrm{I}_{2}$ bound to the anionic $\mathrm{NS}^{-}$. Although the reaction proceeds in a good direction and offers desired products, following the departure of $\mathrm{I}_{2}$, this reaction sequence is significantly endergonic $\left(\Delta G_{R}=12.7 \mathrm{kcal} \mathrm{mol}^{-1}\right)$, while, more importantly, the kinetic barrier is extensive at $\Delta G^{\ddagger}=37.3 \mathrm{kcal} \mathrm{mol}^{-1}$. A more feasible route (Figure 2) involves the sole approach of the $\mathrm{N} 1$ atom in $\mathrm{TMSN}_{3}$ on the mentioned azirine carbon to give the intermediate IN4, with the $-\mathrm{SiMe}_{3}$ moiety bonded to the rest of the azide, a reaction similar to the already described $1 \rightarrow \mathrm{IN} 1$ conversion. The reaction proceeds through the transition state TS4, having a practically formed C-N bond $(2.18 \AA)$ and a significantly departed iodine anion $\mathrm{I}^{-}\left(\mathrm{d}_{\mathrm{C}-\mathrm{I}}=4.18 \AA\right)$, being only $19.9 \mathrm{kcal} \mathrm{mol}^{-1}$ higher in energy than IN3, also containing a $9.9 \mathrm{kcal} \mathrm{mol}^{-1}$ contribution to bring $\mathrm{TMSN}_{3}$ into a reactive complex. Interestingly, $\mathrm{TMSN}_{3}$ addition on the unsaturated C-atom in IN3 is kinetically much more feasible than its analogous addition on the parent alkyne 1, clearly being a result of a higher reactivity of the strained azirine. The formed IN4 with the adjacent $\mathrm{I}^{-}$anion is less stable by $6.6 \mathrm{kcal} \mathrm{mol}^{-1}$ than the preceding IN3, but this process is facilitated by the positive solvation energy of the free $\mathrm{I}^{-}$anion in $\mathrm{MeCN}$, making its departure from the complex thermodynamically favorable $\left(-11.5 \mathrm{kcal} \mathrm{mol}^{-1}\right)$, thus leaving the isolated IN4 as the most stable stationary point hitherto on the profile $\left(\Delta G_{R}=-92.9 \mathrm{kcal} \mathrm{mol}^{-1}\right)$.

As mentioned, the formation of IN4 offers a free $\mathrm{I}^{-}$anion. Given that Yanada observed a change in the mixture color to purplish red [22], attributed to the formation of $\mathrm{I}_{2}$, the potential fate of the formed $\mathrm{I}^{-}$can lead to two different routes, also knowing that the attached $-\mathrm{SiMe}_{3}$ group in IN4 must be cleaved to afford the 2-azide-2H-azirine analogue IN5. In one scenario, $\mathrm{I}^{-}$could engage in a reaction with IN4 as a nucleophile to cleave the $\mathrm{Si}-\mathrm{N}$ bond within azide. The activation energy for this is $\Delta G^{\ddagger}=24.6 \mathrm{kcal} \mathrm{mol}^{-1}$ and offers TMSI $\left(\mathrm{Me}_{3} \mathrm{Si}-\mathrm{I}\right)$ as a byproduct, which departs the complex $\left(-14.4 \mathrm{kcal} \mathrm{mol}^{-1}\right)$ and leaves a highly stable IN5 as a product. However, TMSI was not reported among products under experimental conditions [22], and its likely clearance could occur through the subsequent exergonic reaction with NIS ( $\Delta G_{R}=-19.4 \mathrm{kcal} \mathrm{mol}^{-1}$, Scheme 3$)$, which produces TMS-NS adduct and $\mathrm{I}_{2}$, thus potentially agreeing with experiments. Overall, this reaction sequence $\mathrm{IN} 4+\mathrm{I}^{-}+\mathrm{NIS} \rightarrow \mathrm{IN} 5+$ TMS-NS $+\mathrm{I}_{2}$, apart from the kinetic barrier of $24.6 \mathrm{kcal} \mathrm{mol}^{-1}$, is associated with the thermodynamic change of $-34.3 \mathrm{kcal} \mathrm{mol}^{-1}$, thus suggesting a viable process. Nevertheless, what turns out to be an even more feasible option starts with a favorable exclusion of the formed I- from IN4 $\left(-11.5 \mathrm{kcal} \mathrm{mol}^{-1}\right)$ and undergoes a direct reaction with NIS, to give the expected $\mathrm{I}_{2}$ (Scheme 3) responsible for the observed change in the reaction mixture color [22]. While this reaction is endergonic $\left(+11.6 \mathrm{kcal} \mathrm{mol}^{-1}\right.$, Scheme 3), it produces a nucleophilic succinimide anion $\mathrm{NS}^{-}$, which cleaves the $-\mathrm{SiMe}_{3}$ moiety from IN4, in analogy with its role during the IN1 $\rightarrow \mathrm{IN} 2$ conversion. Bringing $\mathrm{NS}^{-}$to IN4 requires $6.0 \mathrm{kcal} \mathrm{mol}^{-1}$ in free energy and an additional $3.4 \mathrm{kcal} \mathrm{mol}^{-1}$ to arrive at the transition state TS5 describing the simultaneous $\mathrm{Si}-\mathrm{N}$ bond cleavage in azide $(1.92 \AA)$ and Si-N bond formation with $\mathrm{NS}^{-}(2.54 \AA)$. The activation energy for the overall process is $\Delta G^{\ddagger}$ $=21.0 \mathrm{kcal} \mathrm{mol}^{-1}$, being $3.6 \mathrm{kcal} \mathrm{mol}^{-1}$ more favorable than for the first described scenario. In addition, the latter conclusion is further promoted by the remarkably high activation energy of the TMSI + NIS $\rightarrow$ TMS-NS + $\mathrm{I}_{2}$ reaction, occurring in the first scenario, which exceeds $55 \mathrm{kcal} \mathrm{mol}^{-1}$, thus making it very unlikely. Lastly, following the departure of the produced TMS-NS adduct $\left(\Delta G_{R}=-7.4 \mathrm{kcal} \mathrm{mol}^{-1}\right)$, the reaction gives the desired IN5 as a stable intermediate, being the most stable stationary point on the reaction profile up to that point $\left(\Delta G_{R}=-115.6 \mathrm{kcal} \mathrm{mol}^{-1}\right)$. 


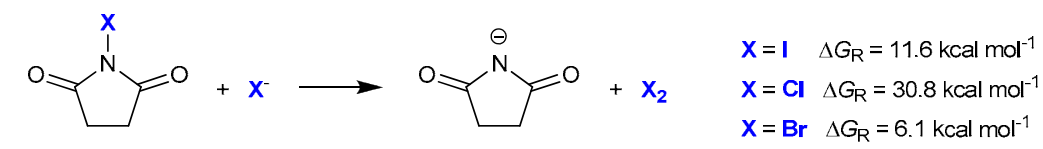

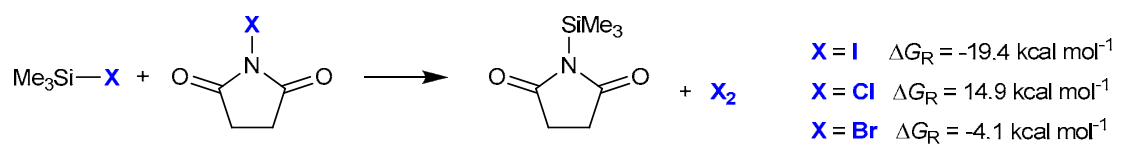

Scheme 3. Two potential routes for the formation of molecular halogens $X_{2}$ observed experimentally. The calculated reaction Gibbs free energies (in $\mathrm{kcal} \mathrm{mol}^{-1}$ ) correspond to the MeCN solution.

Once 2-azide-2H-azirine IN5 is formed, it undergoes intramolecular rearrangement to give two nitriles. In locating the transition state for this process, we have considered (i) the independent cleavage of any of the three bonds within azirine, (ii) the cleavage of the $\mathrm{C}-\mathrm{N}$ (azide) bond, and (iii) various approaches of the attached azide onto the ring. Yet, the only feasible route was cleaving the azide N1-N2 bond, which liberates $\mathrm{N}_{2}$, while the reorganization of the electron density in the rest of the system affords two nitriles as final products (Figure 2). The barrier for this process is $\Delta G^{\ddagger}=33.5 \mathrm{kcal} \mathrm{mol}^{-1}$, being the highest on the reaction profile, thus making this reaction the rate-limiting step. The matching transition state TS6 features a practically departed $\mathrm{N}_{2}$ molecule $\left(\mathrm{d}_{\mathrm{N} 1-\mathrm{N} 2}=1.73 \AA\right.$, Figure 3 ), with its constituting $\mathrm{N}$-atoms at a close-to-bonding distance of $\mathrm{d}_{\mathrm{N} 2-\mathrm{N} 3}=1.11 \AA$, being $1.09 \AA$ in the isolated $\mathrm{N}_{2}$. This directly gives two benzonitriles in a complex with $\mathrm{N}_{2}$, which following a very favorable exclusion of all three products $\left(-12.9 \mathrm{kcal} \mathrm{mol}^{-1}\right)$ gives an exceedingly exergonic total reaction free energy of $\Delta G_{\mathrm{R}}=-191.9 \mathrm{kcal} \mathrm{mol}^{-1}$, thus clearly underlying the thermodynamic feasibility of the overall process.

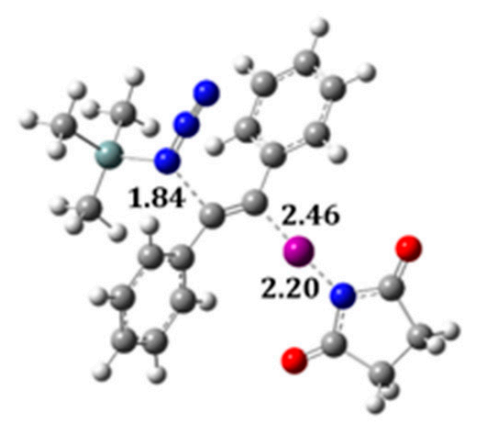

TS1

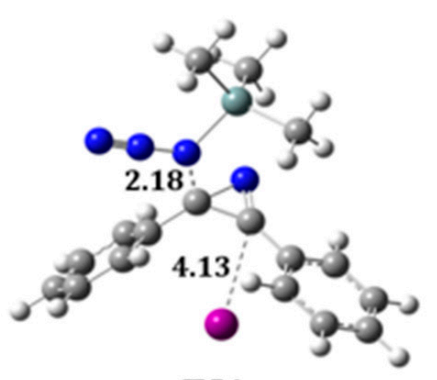

TS4

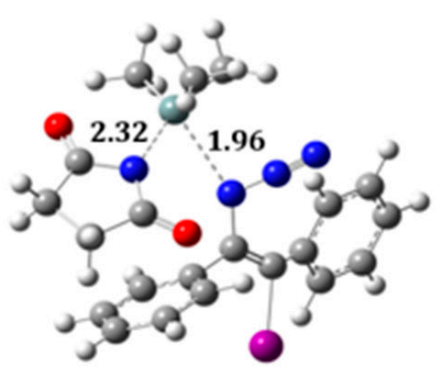

TS2

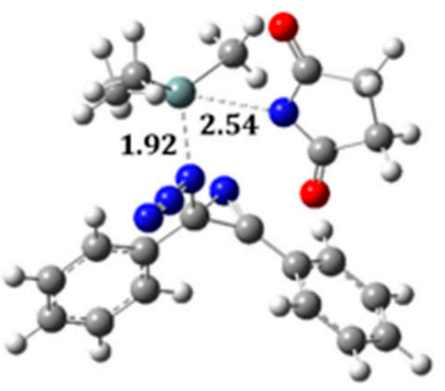

TS5

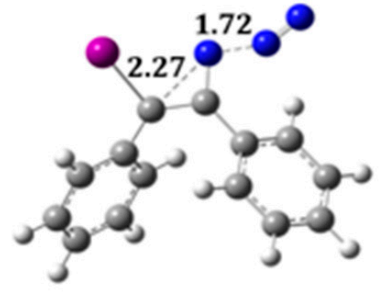

TS3

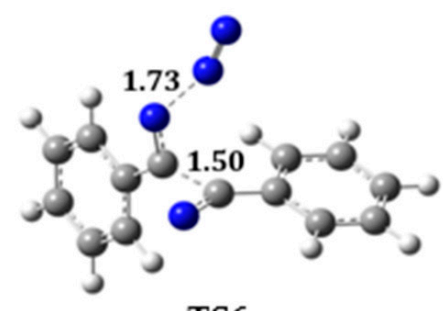

TS6

Figure 3. Transition state geometries during the conversion of 1 into two benzonitriles shown in Figure 2 with relevant bond distances obtained at the M06-2X/6-31+G(d) level of theory.

In concluding this part, it is worth mentioning that, while studying several mechanistic possibilities, the obtained reaction profile (Figure 2) suggests that the conversion of $\mathbf{1}$ into two benzonitriles, oxidized by NIS and using $\mathrm{TMSN}_{3}$ as a nitrogen donor, is a feasible 
process $\left(\Delta G_{R}=-191.9 \mathrm{kcal} \mathrm{mol}^{-1}\right)$ that involves six steps with the rate-limiting exclusion of $\mathrm{N}_{2}$ from the 2-azide- $2 \mathrm{H}$-azirine intermediate IN5 in the last step, linked with the activation barrier of $\Delta G^{\ddagger}=33.5 \mathrm{kcal} \mathrm{mol}^{-1}$. The identified pathway strongly agrees with several experimental observations [22] by (i) providing evidence for the formation of molecular $\mathrm{I}_{2}$ responsible for the change in color, and (ii) rationalizing the need to increase the reaction temperature following the first part of the process. Given the significance of the ratelimiting last step for the description of the entire process, we decided to validate the obtained activation barrier by two additional sets of calculations: (i) by correcting the total electronic energies through single-point calculations with a significantly larger and more flexible 6-311+G(2d,p) basis-set on all atoms, which gave $\Delta G^{\ddagger}=32.2 \mathrm{kcal} \mathrm{mol}^{-1}$, and (ii) by reoptimizing all geometries during the IN5 $\rightarrow$ P conversion in the implicit solvent at the (SMD)/M06-2X/6-31+G(d) level with all parameters for pure $\mathrm{MeCN}$, which gave $\Delta G^{\ddagger}=33.8 \mathrm{kcal} \mathrm{mol}^{-1}$. Such a close match in the obtained barriers lends some credence to the employed computational setup and led us to conclude that the presented reaction profile is likely associated with reliable kinetic and thermodynamic parameters.

\subsection{Reaction on Diphenylacetylene Derivatives with NIS and $\mathrm{TMSN}_{3}$ in Acetonitrile}

In order to further confirm the validity of the proposed mechanism, we considered symmetrical $p$-Me (2) and $p$-CN (3) derivatives of the parent 1 , as well as a terminal analogue 4 (Figure 1), with the idea of supporting the assumptions that electron-donating para-groups facilitate the reaction, as postulated by Yanada (Scheme 1) [22]. At first glance, such behavior would contradict the anticipated effect of these substituents on the stability of the $\mathrm{C} \equiv \mathrm{C}$ bond, as, for example, the electron-donating $p$-Me group should additionally stabilize the central triple bond, thus hindering the conversion. Indeed, our data show that the bond energy in $\mathbf{1}$ is $180.7 \mathrm{kcal} \mathrm{mol}^{-1}$ in $\mathrm{MeCN}$, being further increased to $181.6 \mathrm{kcal}$ $\mathrm{mol}^{-1}$ in 2 . In contrast, the electron-withdrawing $p$-CN group in 3 reduces the strength of the triple bond to $178.8 \mathrm{kcal} \mathrm{mol}^{-1}$, leading us to conclude that the stability of the central $\mathrm{C} \equiv \mathrm{C}$ linkage is not the only, or even the predominant effect governing the outcomes of the studied alkyne $\rightarrow$ nitrile conversion. In order to focus only on the electronic effects of the considered substituents, we have undertaken calculations while maintaining NIS and $\mathrm{TMSN}_{3}$ as reactants, and MeCN as the solvent (Table 1).

Table 1. Relative Gibbs free energies of stationary points during the alkyne $\rightarrow$ nitrile conversion shown in Figure 2 (in $\mathrm{kcal} \mathrm{mol}^{-1}$ ).

\begin{tabular}{|c|c|c|c|c|c|c|c|c|c|}
\hline $\begin{array}{l}\text { Solvent } \\
\text { Oxidant }\end{array}$ & NIS & NIS & NIS & $\begin{array}{l}\text { Acetonitrile } \\
\text { NIS }\end{array}$ & NCS & NBS & NIS & $\begin{array}{l}\text { Toluene } \\
\text { NIS }\end{array}$ & $\begin{array}{l}\text { Water } \\
\text { NIS }\end{array}$ \\
\hline $\begin{array}{c}\text { Nitrogen Source } \\
\text { Alkyne }\end{array}$ & $\begin{array}{c}\mathrm{TMSN}_{3} \\
1\end{array}$ & $\begin{array}{c}\mathrm{TMSN}_{3} \\
2\end{array}$ & $\begin{array}{c}\mathrm{TMSN}_{3} \\
3\end{array}$ & $\begin{array}{c}\mathrm{TMSN}_{3} \\
4\end{array}$ & $\begin{array}{c}\mathrm{TMSN}_{3} \\
2\end{array}$ & $\begin{array}{c}\mathrm{TMSN}_{3} \\
2\end{array}$ & $\begin{array}{l}\mathrm{NaN}_{3} \\
2\end{array}$ & $\begin{array}{c}\mathrm{TMSN}_{3} \\
1\end{array}$ & $\begin{array}{c}\mathrm{TMSN}_{3} \\
\mathbf{1}\end{array}$ \\
\hline \multicolumn{10}{|l|}{ Stationary Point } \\
\hline $\mathrm{R}$ & 0.0 & 0.0 & 0.0 & 0.0 & 0.0 & 0.0 & 0.0 & 0.0 & 0.0 \\
\hline TS1 & 26.8 & 26.8 & 26.8 & 22.7 & 35.8 & 30.0 & 24.7 & 29.6 & 24.5 \\
\hline IN1 & 13.7 & 12.9 & 14.6 & 3.4 & -5.5 & 1.7 & & 16.1 & 9.7 \\
\hline TS2 & 22.1 & 20.7 & 22.2 & 8.4 & 1.0 & 8.3 & & 20.7 & 18.6 \\
\hline IN2 & -36.9 & -37.6 & -37.2 & -43.4 & -57.3 & -50.9 & -50.5 & -38.5 & -38.5 \\
\hline TS3 & -9.0 & -9.3 & -9.4 & -14.3 & -28.5 & -23.3 & -22.2 & -10.6 & -11.2 \\
\hline IN3 & -88.0 & -88.9 & -87.2 & -94.9 & -110.8 & -104.7 & -101.9 & -89.2 & -93.9 \\
\hline TS4 & -68.1 & -71.4 & -62.4 & -66.4 & -78.5 & -73.8 & -90.9 & -62.4 & -72.7 \\
\hline IN4 & -92.9 & -93.8 & -92.9 & -88.1 & -103.4 & -91.4 & & -77.4 & -98.9 \\
\hline TS5 & -71.9 & -73.7 & -72.5 & -69.4 & -64.0 & -76.8 & & -74.9 & -80.2 \\
\hline IN5 & -115.6 & -116.3 & -116.8 & -112.9 & -106.6 & -119.4 & -142.6 & -118.6 & -124.0 \\
\hline TS6 & -82.1 & -82.8 & -83.3 & -79.2 & -73.1 & -85.9 & -109.1 & -84.0 & -91.1 \\
\hline $\mathrm{P}$ & -191.9 & -192.0 & -188.8 & -191.7 & -178.9 & -192.5 & -228.9 & -193.9 & -193.5 \\
\hline Rate-limiting step & $\mathrm{IN} 5 \rightarrow \mathrm{P}$ & $\mathrm{IN} 5 \rightarrow \mathrm{P}$ & IN5 $\rightarrow$ P & $\mathrm{IN} 5 \rightarrow \mathrm{P}$ & IN4 $\rightarrow$ IN5 & $\mathrm{IN} 5 \rightarrow \mathrm{P}$ & $\mathrm{IN} 5 \rightarrow \mathrm{P}$ & IN5 $\rightarrow P$ & IN5 $\rightarrow P$ \\
\hline Activation barrier $\Delta G^{\ddagger}$ & 33.5 & 33.5 & 33.5 & 33.6 & 39.3 & 33.5 & 33.5 & 34.6 & 32.9 \\
\hline
\end{tabular}


Table 1 reveals that the stability of all relevant stationary points in $\mathbf{2}$ and $\mathbf{3}$ is not significantly affected by the para-substitution with either groups, and that the matching conversion proceeds through the same mechanism. Since the rate-limiting step corresponds to the IN5 $\rightarrow$ P transition and involves breaking of the azide N1-N2 bond, the latter appears independent from the electronic features of the distant para-moieties that are clearly too far to exert any notable electronic effect on the mentioned process, which contradicts the assumption proposed by Yanada (Scheme 1) [22]. This is also evident during the IN2 $\rightarrow$ IN3 conversion, which is, surprisingly, most feasible for $3\left(27.7 \mathrm{kcal} \mathrm{mol}^{-1}\right.$ in the activation barrier), followed by $1\left(27.9 \mathrm{kcal} \mathrm{mol}^{-1}\right)$ and $\mathbf{2}\left(28.3 \mathrm{kcal} \mathrm{mol}^{-1}\right)$. Thus, the overall activation barrier for all 1-3 is the same at $\Delta G^{\ddagger}=33.5 \mathrm{kcal} \mathrm{mol}^{-1}$, and not making any difference among systems. In contrast, thermodynamic aspects speak in favor of the $p$-Me derivative 2 , since its reaction free energy is more favorable by $0.1 \mathrm{kcal} \mathrm{mol}^{-1}$, while for 3 it is less favorable by $3.1 \mathrm{kcal} \mathrm{mol}^{-1}$ relative to 1 , in line with the observed reactivity trends [22]. Such small differences might appear confusing, yet these are not unexpected given very small variations in the reported reaction yields [22] that range from $44 \%$ for 1 to only $65 \%$ and $47 \%$ for 2 and the matching $p$-F derivative. Nevertheless, to further strengthen these arguments, let us note that all stationary points during the conversion of $\mathbf{2}$ are consistently more stable than those for $\mathbf{1}$ (Table 1), indicating a more optimal reaction for the former, whereas the same can be concluded for 3, only in the opposite direction. Although Yanada did not consider a system symmetrically substituted with two classical and strong electronwithdrawing groups [22], our data point to a conclusion that such derivatives should be less favorable and would offer lower yields in $\mathrm{MeCN}$, and their consideration will likely be associated with harsher reaction conditions.

\subsection{Reaction on Terminal Alkynes with NIS and $\mathrm{TMSN}_{3}$ in Acetonitrile}

According to experiments [22], terminal alkynes give nitriles in moderate yields, as, for example, 4 offered the matching nitrile in a 51\% yield, being slightly reduced from $84 \%$ when its symmetrical $p$-OMe analogue was used. Our calculations show the initial approach of NIS and $\mathrm{TMSN}_{3}$ onto 4 is more feasible than with any of 1-3 (by $4.1 \mathrm{kcal}$ $\mathrm{mol}^{-1}$ in the activation barrier) and it gives between a 9.5-11.2 $\mathrm{kcal} \mathrm{mol}^{-1}$ more stable intermediate IN1. The negative charge on the terminal $\mathrm{C}(\mathrm{H})$-atom of $-0.24 \mathrm{I} \mathrm{I}$ in 4 , as opposed to practically neutral charge of $-0.06|\mathrm{e}|$ on its vicinal alkyne partner, directs the attack of the electrophilic NIS onto the former site, while the latter C-atom, bearing the p-methoxyphenyl unit, is approached by $\mathrm{TMSN}_{3}$ in a concerted way. An opposite case has a $1.7 \mathrm{kcal} \mathrm{mol}^{-1}$ higher activation barrier, thus is not considered further. Such a significant improvement in the stability of IN1 comes as a result of the reduced steric interferences between $\mathrm{TMSN}_{3}$ and the $\mathrm{H}$-atom on the same carbon, the latter involving a much bulkier phenyl ring in 1-3. The rest of the mechanism proceeds in analogy to internal alkynes, where we notice a $0.8 \mathrm{kcal} \mathrm{mol}^{-1}$ increase in the barrier for the IN2 $\rightarrow$ IN3 conversion, and a $10.9 \mathrm{kcal} \mathrm{mol}^{-1}$ increase for IN3 $\rightarrow \mathrm{IN} 4$, both relative to 2 . Yet, for the rate-limiting IN5 $\rightarrow \mathrm{P}$ step, the kinetic barrier in 4 is increased by $0.1 \mathrm{kcal} \mathrm{mol}^{-1}$ relative to that for 2 , which goes in line with the mentioned tendency that terminal alkynes are less reactive [22], being further prompted by a $0.3 \mathrm{kcal} \mathrm{mol}^{-1}$ lower exergonicity for 4 (Table 1 ). Moreover, the analysis of geometries for the relevant TS6 offers some indication as to why the presence of an aromatic phenyl unit on both alkyne carbons facilitates this step, and why internal alkynes generally give somewhat higher yields than terminal analogues. Namely, the additional phenyl ring in $\mathbf{2}$ acts as an electron-acceptor and extracts the electron density from the azirine ring, thus making all three bonds within the ring in TS6 up to $0.1 \AA$ longer in 2 than in 4, which promotes this ring-opening and helps affording the final products. In conclusion, the obtained insight confirms that the studied reaction strategy can be successfully employed for both internal and terminal alkynes, with the former allowing for slightly more favorable outcomes. 


\subsection{Changing Oxidant to NCS and NBS in Acetonitrile}

After revealing the precise mechanism for the alkyne $\rightarrow$ nitrile conversions, and tying the obtained results in agreement with experimental observations [22], we felt it worthwhile to study the impact of changing the oxidant from NIS into its Cl- and Br-analogues, NCS and NBS, and replacing $\mathrm{TMSN}_{3}$ as a nitrogen source with its sodium alternative $\mathrm{NaN}_{3}$ (Figure 1), with the idea of suggesting guidelines towards even more effective processes. In doing so, we maintained $\mathrm{MeCN}$ as a solvent and focused on the most reactive system 2 as an illustrative example (Table 1).

The approach of both NCS and NBS onto 2 is considerably more demanding than with NIS, as clearly seen in much higher activation barriers for the first step by 9.0 and $3.2 \mathrm{kcal} \mathrm{mol}^{-1}$, respectively, which already makes NCS a very poor alternative, since the initial step with NCS already has a $2.3 \mathrm{kcal} \mathrm{mol}^{-1}$ higher barrier than the whole NIScatalyzed process. Such a trend is closely reflected in the computed $\mathrm{N}$-halogen bond energies of the matching $N$-halogeno-succinimides, being $201.5,176.6$, and $94.1 \mathrm{kcal} \mathrm{mol}^{-1}$ for $\mathrm{Cl}-, \mathrm{Br}-$, and I-analogues, respectively. This shows that the $\mathrm{N}$-halogen bond cleavage is most demanding for NCS, followed by NBS and NIS, which affects the feasibility of the $\mathrm{R} \rightarrow \mathrm{IN} 1$ reaction. Furthermore, let us recall that around $28 \mathrm{kcal} \mathrm{mol}^{-1}$ in the kinetic barrier for systems 1-2 (Table 1) required raising the temperature up to $70{ }^{\circ} \mathrm{C}$ to advance the reaction [22]. In contrast, the values calculated for NBS and NCS initially assume 30.0 and as much as $35.8 \mathrm{kcal} \mathrm{mol}^{-1}$, thus providing a likely reason which led Yanada and co-workers to conclude that "under the same reaction conditions, the use of NBS or NCS instead of NIS failed to give a significant amount of nitrile products" [22]. Moreover, as the reaction proceeds, the obtained insight offers additional reasons supporting such a claim. Specifically, once $\mathrm{Cl}^{-}$is produced, following the IN3 $\rightarrow \mathrm{IN} 4$ conversion with NCS, its departure is exergonic at $13.8 \mathrm{kcal} \mathrm{mol}^{-1}$, being $2.3 \mathrm{kcal} \mathrm{mol}^{-1}$ more favorable than with $\mathrm{I}^{-}$. Yet, the subsequent reaction with NCS, to afford the nucleophilic $\mathrm{NS}^{-}$, is extensively endergonic ( $+30.8 \mathrm{kcal} \mathrm{mol}^{-1}$, Scheme 3$)$, which, together with the approach of NS ${ }^{-}$onto IN4 $\left(+6.1 \mathrm{kcal} \mathrm{mol}^{-1}\right)$ and further $2.4 \mathrm{kcal} \mathrm{mol}^{-1}$ to reach TS5, gives the total activation free energy of $\Delta G^{\ddagger}=39.3 \mathrm{kcal} \mathrm{mol}^{-1}$, being the highest on the entire reaction profile. The latter makes the IN4 $\rightarrow$ IN5 conversion prevailing as the rate-limiting step of the NCS-catalyzed process, being about $6 \mathrm{kcal} \mathrm{mol}^{-1}$ higher than values calculated for NIS (Table 1). In addition, the overall reaction free energy is by $13.1 \mathrm{kcal} \mathrm{mol}^{-1}$ less exergonic with NCS than with NIS. All of this consistently makes NCS a significantly poorer option to facilitate the investigated alkyne $\rightarrow$ nitrile conversion. Alternatively, the stability of stationary points with NBS much closely reflects those with NIS (Table 1). This comes as a result of the fact that the relevant $\mathrm{Br}^{-}+\mathrm{NBS} \rightarrow \mathrm{NS}^{-}+\mathrm{Br}_{2}$ reaction is not so unfavorable as with chlorine, with the reaction free energy being even more favorable, by $5.5 \mathrm{kcal} \mathrm{mol}^{-1}$, than the analogous process for iodine (Scheme 3). This reduces the kinetic barrier for the IN4 $\rightarrow$ IN5 conversion from $20.1 \mathrm{kcal} \mathrm{mol}^{-1}$ with NIS to $14.6 \mathrm{kcal} \mathrm{mol}^{-1}$ with NBS, yet the next conversion of IN5 into P does not depend on the halogenated oxidant, and thus is identical for both NIS and NBS at $\Delta G^{\ddagger}=33.5 \mathrm{kcal} \mathrm{mol}^{-1}$, indicating the rate-limiting step. With all this in mind, we can conclude that the practical usefulness of NBS is similar to NIS at best, likely providing a somewhat poorer choice. On the other hand, all data obtained for NCS are consistent in ruling out this alternative as a viable option.

\subsection{Changing Nitrogen Source to $\mathrm{NaN}_{3}$ in Acetonitrile}

The choice to consider sodium azide $\mathrm{NaN}_{3}$ as a potential replacement for $\mathrm{TMSN}_{3}$ originates in the fact that the azide unit is less strongly bonded to sodium than to the $-\mathrm{SiMe}_{3}$ moiety, which could overcome some difficulties linked with the cleavage of the $-\mathrm{SiMe}_{3}$ group from azide following the nucleophilic attack of $\mathrm{TMSN}_{3}$ during two steps (Figure 2). This is supported by the heterolytic Si-N bond energy of $59.6 \mathrm{kcal} \mathrm{mol}^{-1}$ calculated for $\mathrm{TMSN}_{3}$, being significantly reduced to $13.3 \mathrm{kcal} \mathrm{mol}^{-1}$ in $\mathrm{NaN}_{3}$. Nevertheless, despite such a weak bonding, in order to consistently evaluate reaction profiles with both nitrogendonating reagents on the same footing, we have considered all processes with a full $\mathrm{NaN}_{3}$ 
molecule, although a consideration of only its significantly more nucleophilic and more reactive azide $\mathrm{N}_{3}{ }^{-}$anion could also be warranted, which could likely lead to even more favorable profiles.

Indeed, the overall process with $\mathrm{NaN}_{3}$ requires two steps less than with $\mathrm{TMSN}_{3}$ (Figure 4), since each of the two nucleophilic additions of the former are, beside the formation of a new C(alkyne)-N1(azide) bond, linked with a significant increase in the $\mathrm{Na}-\mathrm{N} 1$ bond, having practically dissociated $\mathrm{Na}^{+}$cation in the produced intermediate, thus no special chemical reactions to detach the latter are needed. Specifically, the initial one-step approach of both $\mathrm{NaN}_{3}$ and NIS onto 2 gives a fully formed intermediate with $\mathrm{Na}^{+}$and $\mathrm{NS}^{-}$well separated from the rest of IN2 at $\mathrm{d}_{\mathrm{Na}-\mathrm{N}}=2.37 \AA$ and $\mathrm{d}_{\mathrm{N}-\mathrm{I}}=2.53 \AA$, being notably elongated from $\mathrm{d}_{\mathrm{Si}-\mathrm{N}}=1.87 \AA$ and $\mathrm{d}_{\mathrm{N}-\mathrm{I}}=2.37 \AA$ when $\mathrm{TMSN}_{3}$ is used. Joining $\mathrm{Na}^{+}$and $\mathrm{NS}^{-}$ to give Na-NS is favorable $\left(-19.0 \mathrm{kcal} \mathrm{mol}^{-1}\right)$, which, together with its positive exclusion $\left(-32.4 \mathrm{kcal} \mathrm{mol}^{-1}\right)$, leads to the first step of the $\mathrm{NaN}_{3}$-enabled reaction being extensively exergonic at $\Delta G_{R}=-50.5 \mathrm{kcal} \mathrm{mol}^{-1}$ (Figure 4). Additionally, all of this offers a $2.1 \mathrm{kcal}$ $\mathrm{mol}^{-1}$ lower barrier to reach the first transition state TS1 with $\mathrm{NaN}_{3}$ than with $\mathrm{TMSN}_{3}$, already hinting at an improved practical usefulness of the former. The reason for that lies in the fact that the reaction with $\mathrm{NaN}_{3}$ proceeds through a significantly more polar transition state TS1, which is obviously favored in a solvent of such a polarity (MeCN). To support this claim, let us mention that in TS1 with $\mathrm{TMSN}_{3}$, the matching charges on the azide $\mathrm{N}_{3}{ }^{-}$ and $-\mathrm{SiMe}_{3}$ fragments are -0.31 and $0.69 \mathrm{I} \mathrm{e} \mid$, respectively, being appreciably increased to -0.67 and $0.98 \mathrm{I}$ el on $\mathrm{N}_{3}{ }^{-}$and $\mathrm{Na}^{+}$with $\mathrm{NaN}_{3}$. Analogously, the charges on $\mathrm{I}^{+}$cation and $\mathrm{NS}^{-}$anion are 0.31 and -0.53 | $\mathrm{e} \mid$ with $\mathrm{TMSN}_{3}$, being increased to 0.33 and -0.58 le $\mid$ with $\mathrm{NaN}_{3}$. Therefore, a much higher nucleophilicity of $\mathrm{NaN}_{3}$ and its easier tendency to liberate the azide relative to $\mathrm{TMSN}_{3}$, together with a polar nature of TS1 facilitate the approach of $\mathrm{NaN}_{3}$ and NIS onto 2. This also suggests it would be worth considering performing this reaction in even more polar solvents, provided it is not hindered by the stability of reagents or any other difficulty. This notion motivated us to inspect the effect of different solvents on the outcomes of the proposed reaction, which will be discussed later in the text.

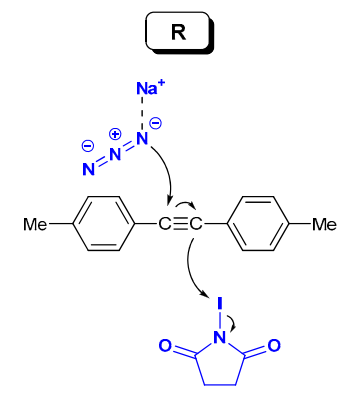

0.0

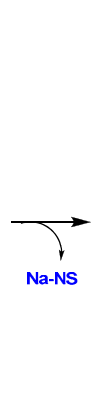

24.7 TS1 $_{\text {T }}$
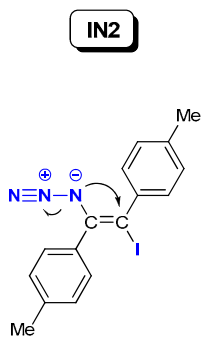

$-50.5$
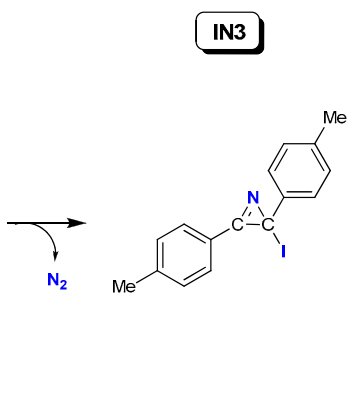

$-22 .{ }^{\mathrm{TS} 3}$

$-101.9$

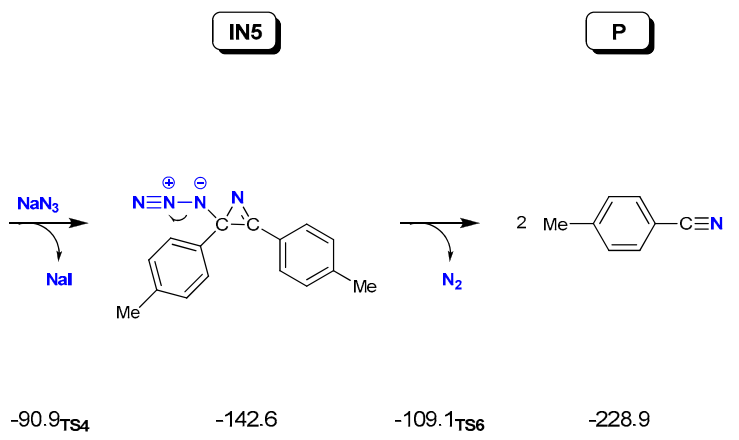

Figure 4. Reaction mechanism for the conversion of 2 with NIS and $\mathrm{NaN}_{3}$. Relative Gibbs free energies (in $\mathrm{kcal} \mathrm{mol}^{-1}$ ) correspond to the MeCN solution. TS and IN denote transition states and intermediates, while R and P stand for reactants and products. Graphical representation of the reaction profile is given as Figure S2.

Once IN2 is formed, it undergoes the same intramolecular rearrangement with the exclusion of $\mathrm{N}_{2}$ to afford IN3 (Figure 4). The next step involves a slight endergonic inclusion of another $\mathrm{NaN}_{3}\left(+0.9 \mathrm{kcal} \mathrm{mol}^{-1}\right)$ and further $10.1 \mathrm{kcal} \mathrm{mol}^{-1}$ to reach the transition state TS4 for its addition onto azirine. The latter gives a free $\mathrm{I}^{-}$anion, which joins with the liberated $\mathrm{Na}^{+}$to give $\mathrm{NaI}$ through an exergonic reaction $\left(-8.2 \mathrm{kcal} \mathrm{mol}^{-1}\right)$. The exclusion of $\mathrm{NaI}$ is further exergonic $\left(-34.9 \mathrm{kcal} \mathrm{mol}^{-1}\right)$, offering the 2-azide- $2 \mathrm{H}$-azirine intermediate IN5 very low on the energy profile (Figure 4 ). The last step again sees the exclusion of $\mathrm{N}_{2}$, which furnishes desired nitriles. In analogy to the $\mathrm{TMSN}_{3}$-enabled reaction, this process is linked with the same activation barrier of $\Delta G^{\ddagger}=33.5 \mathrm{kcal} \mathrm{mol}^{-1}$, again being the rate-limiting step. Yet, in this case, the reaction is by as much as $36.9 \mathrm{kcal} \mathrm{mol}^{-1}$ more exergonic $\left(\Delta G_{R}=-228.9 \mathrm{kcal} \mathrm{mol}^{-1}\right)$, thus indicating its thermodynamic dominance and 
a likely preference for the use of $\mathrm{NaN}_{3}$. With all this, we can conclude that the reaction with $\mathrm{NaN}_{3}$ proceeds through only four steps with the rate-limiting process identical to that when $\mathrm{TMSN}_{3}$ is used yet being significantly thermodynamically more favored. This justifies Yanada's statement that "the use of sodium azide instead of $\mathrm{TMSN}_{3}$ was also found effective for the triple bond cleavage reaction" [22], knowing that the use of $\mathrm{NaN}_{3}$ offered comparable nitrile's yields, but without the need to heat the mixture above room temperature to finish the reaction, as was the case with $\mathrm{TMSN}_{3}$. All of this firmly promotes the use of $\mathrm{NaN}_{3}$ in the proposed alkyne $\rightarrow$ nitrile transformation, which is recommended for future experimental evaluations.

\subsection{Changing Solvent Polarity}

Lastly, we examined the impact of the solvent polarity on the reaction outcomes. In doing so, we considered toluene and water as cases with lower and higher polarity than MeCN, taking 1 as an illustrative example, together with NIS and TMSN 3 (Table 1). We note that the obtained insight should direct towards more optimal solvents, rather than exclusively promoting any of the employed two solvents as only alternatives.

The initial step $\mathrm{R} \rightarrow \mathrm{IN} 1$ already reveals notable differences among solvents. Due to the described polar nature of TS1, it is not surprising that the matching activation energy is lowest in the most polar water at $\Delta G^{\ddagger}=24.5 \mathrm{kcal} \mathrm{mol}^{-1}$, to be increased to $26.8 \mathrm{kcal}$ $\mathrm{mol}^{-1}$ in MeCN, and further to $29.6 \mathrm{kcal} \mathrm{mol}^{-1}$ in toluene, in line with a decrease in the solvent polarity. This offers a very polar intermediate IN1 (Figure 2), which is again most stable in water. The next step sees the approach of anionic $\mathrm{NS}^{-}$to the attached azide, which decreases the polarity of the system, thus being most feasible in toluene, requiring only $4.5 \mathrm{kcal} \mathrm{mol}^{-1}\left(8.4 \mathrm{kcal} \mathrm{mol}^{-1}\right.$ in $\mathrm{MeCN}$ and $8.9 \mathrm{kcal} \mathrm{mol}^{-1}$ in $\left.\mathrm{H}_{2} \mathrm{O}\right)$ to reach a highly stable intermediate IN2. The exclusion of the formed TMS-NS complex is more favorable by $1.6 \mathrm{kcal} \mathrm{mol}^{-1}$ in toluene than in $\mathrm{H}_{2} \mathrm{O}$, thus showing equal stability of the matching IN2 in both solvents. The following rearrangement of IN2 is found within $1 \mathrm{kcal} \mathrm{mol}^{-1}$ in the kinetic barrier in all three solvents, and offers IN3, being most stable in water. The next step is most feasible in MeCN $\left(\Delta G^{\ddagger}=19.9 \mathrm{kcal} \mathrm{mol}^{-1}\right.$, while 21.1 and $26.8 \mathrm{kcal} \mathrm{mol}^{-1}$ in $\mathrm{H}_{2} \mathrm{O}$ and toluene), because of the least demanding inclusion of $\mathrm{TMSN}_{3}$ into the reactive complex with IN3 in the former. This gives a polar intermediate IN4, again being most stable in water and least stable in toluene, which has a dominant contribution in the energy required to exclude the formed $\mathrm{I}^{-}$anion from the system, being most exergonic in water $\left(-12.9 \mathrm{kcal} \mathrm{mol}^{-1}\right)$ and even highly endergonic in toluene $\left(+19.2 \mathrm{kcal} \mathrm{mol}^{-1}\right)$. In addition, the following reaction of $\mathrm{I}^{-}$with NIS, which gives $\mathrm{I}_{2}$ and a nucleophilic $\mathrm{NS}^{-}$, together with the energy required to bring the latter into the reactive complex with IN4, is by far most favorable in toluene $\left(-21.7 \mathrm{kcal} \mathrm{mol}^{-1}\right)$, which makes the IN4 $\rightarrow$ IN5 conversion an almost barrier-less process in that solvent $\left(\Delta G^{\ddagger}=2.5 \mathrm{kcal} \mathrm{mol}^{-1}\right)$, whereas it costs 18.7 and $21.0 \mathrm{kcal} \mathrm{mol}^{-1}$ to analogously afford IN5 in $\mathrm{H}_{2} \mathrm{O}$ and $\mathrm{MeCN}$, respectively. There, the exclusion of the formed TMS-NS is most favorable in $\mathrm{H}_{2} \mathrm{O}$, thus the highest stability of IN5 in that solvent. The last conversion of the 2-azide- $2 \mathrm{H}$-azirine intermediate IN5 into the final nitriles represents the overall rate-limiting step in all three solvents. As described, the matching transition state TS6 involves the cleavage of the azide N1-N2 bond, followed by the liberation of the molecular $\mathrm{N}_{2}$, and the reorganization of the electron density within the azirine ring, which precedes the cleavage of several of its bonds to afford the final products P. As such, TS6 is highly polar in nature and is most favored in water, as seen in the calculated solvation free energies of TS6 being $-14.0,-12.1$, and $-7.9 \mathrm{kcal} \mathrm{mol}^{-1}$ in $\mathrm{H}_{2} \mathrm{O}$, $\mathrm{MeCN}$, and toluene, respectively. As a result, the activation free energy for this step, and the whole process, is lowest in water at $\Delta G^{\ddagger}=32.9 \mathrm{kcal} \mathrm{mol}^{-1}$, to be increased to $33.5 \mathrm{kcal}$ $\mathrm{mol}^{-1}$ in MeCN and further to $34.6 \mathrm{kcal} \mathrm{mol}^{-1}$ in the least polar toluene. Additionally, this goes in line with the calculated increase in the overall reaction exergonicity, which is more favorable by $1.6 \mathrm{kcal} \mathrm{mol}^{-1}$ in $\mathrm{H}_{2} \mathrm{O}$ than in $\mathrm{MeCN}$. This is found in excellent agreement with what was observed during the Ag-catalyzed conversion of $p$-methoxy phenylacetylene with $\mathrm{TMSN}_{3}$ [21], which was more efficient in DMSO (81\%) than in less polar DMF (58\%). 
All of this strongly promotes solvents more polar than $\mathrm{MeCN}$ as better options to advance the entire alkyne $\rightarrow$ nitrile conversion, and are recommended for future experiments.

\section{Calculation Methods}

All structures were optimized by a very efficient density functional theory M06-2X approach together with the $6-31+G(d)$ basis set on all atoms except halogens, which were treated with a larger 6-311G $(\mathrm{d}, \mathrm{p})$ basis set downloaded from the Basis Set Exchange database [58]. Thermal corrections were extracted from the matching frequency calculations without the scaling factors, so that all reported values correspond to Gibbs free energies at room temperature. To account for the solvent effects, the obtained energies were corrected for the Gibbs solvation energies employing the SMD polarizable continuum model at the same level of theory. The choice of this computational setup was prompted by its success in reproducing kinetic and thermodynamic parameters of various organic [59-61], organometallic [62-65], and enzymatic reactions [66,67], being particularly accurate for relative trends among similar reactants, which is the focus here. All transition state structures were located using the scan procedure, employing both 1D and 2D scans, the latter specifically utilized to consider the possibility for concerted or one-step mechanisms. The validity of all transition states was confirmed through both the vibrational analysis and IRC calculations in both directions that identified the matching reactants and products. Atomic charges were obtained through the natural bond orbital (NBO) analysis [68]. All calculations were performed with the Gaussian 16 software [69].

\section{Conclusions}

DFT calculations considered several mechanistic possibilities and demonstrated that a conversion of diphenylacetylene 1 into two benzonitriles, oxidized by NIS and utilizing $\mathrm{TMSN}_{3}$ as a nitrogen donor, is a feasible process involving six reaction steps, with the rate-limiting exclusion of molecular nitrogen from the 2-azide- $2 \mathrm{H}$-azirine intermediate IN5 in the last step, associated with the activation barrier of $\Delta G^{\ddagger}=33.5 \mathrm{kcal} \mathrm{mol}^{-1}$ and the reaction free energy of $\Delta G_{R}=-191.9 \mathrm{kcal} \mathrm{mol}^{-1}$ in $\mathrm{MeCN}$. The proposed reaction pathway strongly agrees with several experimental observations [22], by (i) providing evidence for the formation of the molecular $\mathrm{I}_{2}$, seen as a change in the reaction mixture color as the reaction proceeds to purplish red, and (ii) interpreting why the first part of the process occurs under room temperature, while the second part proceeds only after heating the mixture up to $70{ }^{\circ} \mathrm{C}$. We also confirmed that para-electron-donating groups facilitate the reaction, but showed this is not a kinetic effect channelized through the substituent electronic contributions, but rather a thermodynamic effect seen in the highest $\Delta G_{R}=-192.0 \mathrm{kcal} \mathrm{mol}^{-1}$ for the $p$-Me derivative 2 , to be reduced to -191.9 and $-188.8 \mathrm{kcal} \mathrm{mol}^{-1}$ in the unsubstituted 1 and its $p$-CN derivative 3 . The proposed mechanism also helped in suggesting that this reaction strategy can successfully be employed for both internal and terminal alkynes, and turned useful in rationalizing a slightly more favorable outcome with the former [22], as evidenced by a $0.1 \mathrm{kcal} \mathrm{mol}^{-1}$ lower activation barrier and a $0.3 \mathrm{kcal} \mathrm{mol}^{-1}$ higher exergonicity calculated for the internal alkyne 2 relative to its terminal counterpart 4 .

As an extension of Yanada's work, we revealed that other halogen-derived succinimides, NCS and NBS, provide poor options to replace NIS as an oxidant, most dominantly because of notably higher $\mathrm{N}$-halogen bond dissociation energies, but also because of unfavorable side reactions $\mathrm{X}^{-}+\mathrm{NXS} \rightarrow \mathrm{X}_{2}+\mathrm{NS}^{-}$that precede the fifth reaction step, being the least favorable for $\mathrm{Cl}^{-}\left(\Delta G_{\mathrm{R}}=+30.8 \mathrm{kcal} \mathrm{mol}^{-1}\right)$, yielding the enhanced activation free energy of $\Delta G^{\ddagger}=39.3 \mathrm{kcal} \mathrm{mol}^{-1}$. In contrast, replacing nitrogen-donating $\mathrm{TMSN}_{3}$ with $\mathrm{NaN}_{3}$ reduced the number of the reaction steps to four and increased the overall reaction exergonicity to $\Delta G_{R}=-228.9 \mathrm{kcal} \mathrm{mol}^{-1}$, promoting the latter as a viable alternative to facilitate the process, and explaining comparable product yields when the reaction is performed entirely at room temperature with that nitrogen-donating system.

Lastly, we showed that the rate-limiting rearrangement of the 2-azide- $2 \mathrm{H}$-azirine intermediate IN5 into the final products proceeds through a polar transition state, and 
is, as such, additionally stabilized when solvents of higher polarity than $\mathrm{MeCN}$ are used. Water, as an illustrative example, reduces the activation free energy by $0.6 \mathrm{kcal} \mathrm{mol}^{-1}$ and increases the reaction free energy by $-1.6 \mathrm{kcal} \mathrm{mol}^{-1}$ relative to $\mathrm{MeCN}$, thus consistently suggesting an increase in the solvent polarity as another useful route to advance the investigated reaction strategy towards even more efficient processes.

Supplementary Materials: The following are available online at https:/ /www.mdpi.com/1422-0 067/22/6/3193/s1: Cartesian coordinates, total molecular energies, thermal corrections and the number of imaginary frequencies for all computed systems; Figure S1: Graphical representation of the reaction profile for the conversion of diphenylacetylene 1 to benzonitrile with NIS as an oxidant and $\mathrm{TMSN}_{3}$ as a nitrogen source in MeCN.; Figure S2: Graphical representation of the reaction profile for the conversion of $\mathbf{2}$ to $p$-Me-benzonitrile with NIS as an oxidant and $\mathrm{NaN}_{3}$ as a nitrogen source in $\mathrm{MeCN}$.

Author Contributions: Conceptualization, R.V.; validation, L.H. and R.V.; formal analysis, L.H. and R.V.; investigation, L.H.; data curation, L.H.; writing—original draft preparation, R.V.; writingreview and editing, L.H. and R.V.; visualization, L.H.; supervision, R.V.; funding acquisition, R.V. All authors have read and agreed to the published version of the manuscript.

Funding: This work was supported by CAT PHARMA (KK.01.1.1.04.0013), a project co-financed by the Croatian Government and the European Union through the European Regional Development Fund-the Competitiveness and Cohesion Operational Programme.

Institutional Review Board Statement: Not applicable.

Informed Consent Statement: Not applicable.

Data Availability Statement: Data is contained within the article or Supplementary Material.

Acknowledgments: L.H. wishes to thank the Croatian Science Foundation for a doctoral stipend through the Career Development Project for Young Researchers. We thank the Zagreb University Computing Centre for computational resources on the ISABELLA cluster.

Conflicts of Interest: The authors declare no conflict of interest. The sponsors had no role in the design, execution, interpretation, or writing of the study.

\section{References}

1. Xiong, H.; Ramkumar, N.; Chiou, M.F.; Jian, W.; Li, Y.; Su, J.H.; Zhang, X.; Bao, H. Iron-catalyzed carboazidation of alkenes and alkynes. Nat. Commun. 2019, 10, 122. [CrossRef]

2. Mahmudov, K.T.; Gurbanov, A.V.; Guseinov, F.I; da Silva, M.F.C.G. Noncovalent interactions in metal complex catalysis. Coord. Chem. Rev. 2019, 387, 32-46. [CrossRef]

3. Wen, H.; Liu, G.; Huang, Z. Recent advances in tridentate iron and cobalt complexes for alkene and alkyne hydrofunctionalizations. Coord. Chem. Rev. 2019, 386, 138. [CrossRef]

4. Liu, B.; Ning, Y.; Virelli, M.; Zanoni, G.; Anderson, E.A.; Bi, X. Direct Transformation of Terminal Alkynes into Amidines by a Silver-Catalyzed Four-Component Reaction. J. Am. Chem. Soc. 2019, 141, 1593-1598. [CrossRef]

5. Haley, M.M. Modern Alkyne Chemistry: Catalytic and Atom-Economic Transformations; Trost, B.M., Li, C.-J., Eds.; Wiley: New York, NY, USA, 2014.

6. Mizushima, E.; Sato, K.; Hayashi, T.; Tanaka, M. Highly efficient AuI-catalyzed hydration of alkynes. Angewv. Chem. Int. Ed. Engl. 2002, 41, 4563. [CrossRef]

7. Marion, N.; Ramón, R.S.; Nolan, S.P. [(NHC)AuI]-Catalyzed Acid-Free Alkyne Hydration at Part-per-Million Catalyst Loadings. J. Am. Chem. Soc. 2009, 131, 448. [CrossRef] [PubMed]

8. Zhang, C.; Jiao, N. Dioxygen Activation under Ambient Conditions: Cu-Catalyzed Oxidative Amidation-Diketonization of Terminal Alkynes Leading to $\alpha$-Ketoamides. J. Am. Chem. Soc. 2010, 132, 28-29. [CrossRef] [PubMed]

9. Jung, M.E.; Deng, G. Synthesis of $\alpha$-Diketones from Alkylaryl- and Diarylalkynes Using Mercuric Salts. Org. Lett. 2014, 16, 2142-2145. [CrossRef] [PubMed]

10. Jiang, Q.; Zhao, A.; Xu, B.; Jia, J.; Liu, X.; Guo, C. PIFA-Mediated Esterification Reaction of Alkynes with Alcohols via Oxidative Cleavage of Carbon Triple Bonds. J. Org. Chem. 2014, 79, 2709-2715. [CrossRef]

11. Kolle, S.; Batra, S. Transformations of alkynes to carboxylic acids and their derivatives via $\mathrm{C} \equiv \mathrm{C}$ bond cleavage. Org. Biomol. Chem. 2016, 14, 11048-11060. [CrossRef]

12. Dighe, S.U.; Batra, S. Visible Light-Induced Iodine-Catalyzed Transformation of Terminal Alkynes to Primary Amides via $\mathrm{C} \equiv \mathrm{C}$ Bond Cleavage under Aqueous Conditions. Adv. Synth. Catal. 2016, 358, 500. [CrossRef] 
13. Song, S.; Li, X.; Sun, X.; Yuan, Y.; Jiao, N. Efficient bromination of olefins, alkynes, and ketones with dimethyl sulfoxide and hydrobromic acid. Green Chem. 2015, 17, 3285-3289. [CrossRef]

14. Ferris, T.; Carroll, L.; Mease, R.C.; Spivey, A.C.; Aboagye, E.O. Iodination of terminal alkynes using $\mathrm{KI} / \mathrm{CuSO}_{4}-\mathrm{A}$ facile method with potential for radio-iodination. Tetrahedron Lett. 2019, 60, 936-939. [CrossRef]

15. Liu, Y.; Song, F.; Guo, S. Cleavage of a Carbon-Carbon Triple Bond via Gold-Catalyzed Cascade Cyclization/Oxidative Cleavage Reactions of (Z)-Enynols with Molecular Oxygen. J. Am. Chem. Soc. 2006, 128, 11332-11333. [CrossRef]

16. Zhou, P.; Wang, J.Y.; Zhang, T.S.; Li, G.; Hao, W.J.; Tu, S.J.; Jiang, B. Arylacetylenes as two-carbon synthons: Synthesis of eight-membered rings via $C \equiv C$ bond cleavage. Chem. Commun. 2018, 54, 164. [CrossRef] [PubMed]

17. Liao, Y.Y.; Gao, Y.C.; Zheng, W.; Tang, R.Y. Oxidative Radical Cyclization of $N$-methyl- $N$-arylpropiolamide to Isatins via Cleavage of the Carbon-carbon Triple Bond. Adv. Synth. Catal. 2018, 360, 3391-3400. [CrossRef]

18. Park, Y.T.; Park, J.W.; Jun, C.H. Metal-organic cooperative catalysis in C-H and C-C bond activation and its concurrent recovery. Acc. Chem. Res. 2008, 41, 222. [CrossRef] [PubMed]

19. Wang, T.; Jiao, N. Direct approaches to nitriles via highly efficient nitrogenation strategy through C-H or C-C bond cleavage. Acc. Chem. Res. 2014, 47, 1137. [CrossRef]

20. Dutta, U.; Lupton, D.W.; Maiti, D. Aryl Nitriles from Alkynes Using tert-Butyl Nitrite: Metal-Free Approach to C $\equiv$ C Bond Cleavage. Org. Lett. 2016, 18, 860-863. [CrossRef]

21. Shen, T.; Wang, T.; Qin, C.; Jiao, N. Silver-catalyzed nitrogenation of alkynes: A direct approach to nitriles through C $\equiv \mathrm{C}$ bond cleavage. Angew. Chem. Int. Ed. Engl. 2013, 52, 6677-6680. [CrossRef]

22. Okamoto, N.; Ishikura, M.; Yanada, R. Cleavage of Carbon-Carbon Triple Bond: Direct Transformation of Alkynes to Nitriles. Org. Lett. 2013, 15, 2571-2573. [CrossRef] [PubMed]

23. Keerthika, K.; Nath, S.; Geetharani, K. Transition-metal-free trifluoromethylative difunctionalization of olefins and alkynes: Approaches and challenges ahead. Catal. Sci. Technol. 2020, 10, 7142-7159. [CrossRef]

24. Su, D.S.; Zhang, J.; Frank, B.; Thomas, A.; Wang, X.; Paraknowitsch, J.; Schlögl, R. Metal-free heterogeneous catalysis for sustainable chemistry. ChemSusChem 2010, 3, 169-180. [CrossRef]

25. Lin, Y.; Song, Q. Cleavage of the Carbon-Carbon Triple Bonds of Arylacetylenes for the Synthesis of Arylnitriles without a Metal Catalyst. Eur. J. Org. Chem. 2016, 2016, 3056-3059. [CrossRef]

26. Asakawa, H.; Lee, K.H.; Lin, Z.; Yamashita, M. Facile scission of isonitrile carbon-nitrogen triple bond using a diborane(4) reagent. Nat. Commun. 2014, 5, 4245. [CrossRef]

27. Chan, A.P.Y.; Sergeev, A.G. Metal-mediated cleavage of unsaturated C-C bonds. Coord. Chem. Rev. 2020, 413, 213213. [CrossRef]

28. Qin, C.; Su, Y.; Shen, T.; Shi, X.; Jiao, N. Splitting a Substrate into Three Parts: Gold-Catalyzed Nitrogenation of Alkynes by C-C and $\mathrm{C} \equiv \mathrm{C}$ Bond Cleavage. Angew. Chem. 2016, 55, 350-354. [CrossRef] [PubMed]

29. Wang, A.; Jiang, H. Palladium-Catalyzed Cleavage Reaction of Carbon-Carbon Triple Bond with Molecular Oxygen Promoted by Lewis Acid. J. Am. Chem. Soc. 2008, 130, 5030-5031. [CrossRef]

30. Liu, Q.; Chen, P.; Liu, G. Palladium-Catalyzed C-C Triple Bond Cleavage: Efficient Synthesis of 4H-Benzo[d][1,3]oxazin-4-ones. ACS Catal. 2013, 3, 178-181. [CrossRef]

31. Shimada, T.; Yamamoto, Y. Carbon-Carbon Bond Cleavage of Diynes through the Hydroamination with Transition Metal Catalysts. J. Am. Chem. Soc. 2003, 125, 6646-6647. [CrossRef]

32. Datta, S.; Chang, C.L.; Yeh, K.L.; Liu, R.S. A New Ruthenium-Catalyzed Cleavage of a Carbon-Carbon Triple Bond: Efficient Transformation of Ethynyl Alcohol into Alkene and Carbon Monoxide. J. Am. Chem. Soc. 2003, 125, 9294-9295. [CrossRef] [PubMed]

33. Jun, C.H.; Lee, H.; Lim, S.G. The C-C bond activation and skeletal rearrangement of cycloalkanone imine by Rh (I) catalysts. J. Am. Chem. Soc. 2001, 123, 751-752. [CrossRef] [PubMed]

34. Huang, X.; Li, X.; Jiao, N. Copper-catalyzed direct transformation of simple alkynes to alkenyl nitriles via aerobic oxidative $\mathrm{N}$-incorporation. Chem. Sci. 2015, 6, 6355-6360. [CrossRef]

35. The Cyano Group; Rappoport, Z. (Ed.) Wiley: London, UK, 1970.

36. Fadda, A.A.; Mukhtar, M.M.; Refat, H.M. Utility of new activated nitriles in the synthesis of some new heterocyclic compounds. Am. J. Org. Chem. 2012, 2, 32-40. [CrossRef]

37. Ghosh, T.; Si, A.; Misra, A.K. Facile Transformation of Nitriles into Thioamides: Application to C-Glycosyl Nitrile Derivatives. ChemistrySelect 2017, 2, 1366-1369. [CrossRef]

38. Fleming, F.F.; Lihua, Y.; Ravikumar, P.C.; Funk, L.; Shook, B.C. Nitrile-containing pharmaceuticals: Efficacious roles of the nitrile pharmacophore. J. Med. Chem. 2010, 53, 7902-7917. [CrossRef]

39. Colombier, M.A.; Molina, J.M. Doravirine: A review. Curr. Opin. HIV AIDS 2018, 13, 308-314. [CrossRef]

40. Nassereddine, S.; Lap, C.J.; Tabbara, I.A. Evaluating ivosidenib for the treatment of relapsed/refractory AML: Design, development, and place in therapy. Onco. Targets Ther. 2018, 12, 303-308. [CrossRef]

41. Yang, J.; Gong, W. Lorlatinib for the treatment of anaplastic lymphoma kinase-positive non-small cell lung cancer. Expert Rev. Clin. Pharmacol. 2019, 12, 173-178. [CrossRef] [PubMed]

42. Miller, J.S.; Manson, J.L. Designer magnets containing cyanides and nitriles. Acc. Chem. Res. 2001, 34, 563-570. [CrossRef] [PubMed] 
43. Goujon, L.J.; Khaldi, A.; Maziz, A.; Plesse, C.; Nguyen, G.T.M.; Aubert, P.H.; Vidal, F.; Chevrot, C.; Teyssié, D. Flexible Solid Polymer Electrolytes Based on Nitrile Butadiene Rubber/Poly (ethylene oxide) Interpenetrating Polymer Networks Containing Either LiTFSI or EMITFSI. Macromolecules 2011, 44, 9683-9691. [CrossRef]

44. Fleming, F.F.; Wang, Q. Unsaturated nitriles: Conjugate additions of carbon nucleophiles to a recalcitrant class of acceptors. Chem. Rev. 2003, 103, 2035-2078. [CrossRef]

45. Sandmeyer, T. Ueber die Ersetzung der Amidgruppe durch Chlor in den aromatischen Substanzen. Chem. Ber. 1884, 17, 1633-1635. [CrossRef]

46. Rosenmund, K.W.; Struck, E. Das am Ringkohlenstoff gebundene Halogen und sein Ersatz durch andere Substituenten. I. Mitteilung: Ersatz des Halogens durch die Carboxylgruppe. Chem. Ber. 1919, 52, 1749-1756. [CrossRef]

47. Ellis, G.P.; Romney-Alexander, T. Cyanation of aromatic halides. Chem. Rev. 1987, 87, 779-794. [CrossRef]

48. Erker, T.; Nemec, S. Palladium-Catalyzed Cyanation Reactions of Thiophene Halides. Synthesis 2004, 1, $23-25$.

49. Anbarasan, P.; Schareina, T.; Beller, M. Recent developments and perspectives in palladium-catalyzed cyanation of aryl halides: Synthesis of benzonitriles. Chem. Soc. Rev. 2011, 40, 5049-5067. [CrossRef] [PubMed]

50. Cohen, D.T.; Buchwald, S.L. Mild Palladium-Catalyzed Cyanation of (Hetero)aryl Halides and Triflates in Aqueous Media. Org. Lett. 2015, 17, 202-205. [CrossRef] [PubMed]

51. Bisseret, P.; Duret, G.; Blanchard, N. Chopping unfunctionalized carbon-carbon bonds: A new paradigm for the synthesis of organonitriles. Org. Chem. Front. 2014, 1, 825-833. [CrossRef]

52. John, P.C.S.; Guan, Y.; Kim, Y.; Kim, S.; Paton, R.S. Prediction of organic homolytic bond dissociation enthalpies at near chemical accuracy with sub-second computational cost. Nat. Commun. 2020, 11, 2328. [CrossRef]

53. Jasiński, R.; Dresler, E. On the Question of Zwitterionic Intermediates in the [3 + 2] Cycloaddition Reactions: A Critical Review. Organics 2020, 1, 5. [CrossRef]

54. García-Lacuna, J.; Domínguez, G.; Pérez-Castells, J. Flow Chemistry for Cycloaddition Reactions. ChemSusChem 2020, $13,1$. [CrossRef] [PubMed]

55. Wu, J.-L.; Chiou, W.-H. Diastereocontrolled Formal Syntheses of ( \pm -Lepadiformines A, B, and C and the Divergent Synthesis of 2-epi-Lepadiformine C through Unexpected Double Consecutive Epimerizations. J. Org. Chem. 2020, 85, 9051-9063. [CrossRef]

56. Krištofíková, D.; Modrocká, V.; Mečiarová, M.; Šebesta, R. Green Asymmetric Organocatalysis. ChemSusChem 2020, $13,2828$. [CrossRef] [PubMed]

57. Gawronski, J.; Wascinska, N.; Gajewy, J. Recent Progress in Lewis Base Activation and Control of Stereoselectivity in the Additions of Trimethylsilyl Nucleophiles. Chem. Rev. 2008, 108, 5227-5252. [CrossRef]

58. Pritchard, B.P.; Altarawy, D.; Didier, B.; Gibson, T.D.; Windus, T.L. A New Basis Set Exchange: An Open, Up-to-date Resource for the Molecular Sciences Community. J. Chem. Inf. Model. 2019, 59, 4814-4820. [CrossRef] [PubMed]

59. Ptiček, L.; Hok, L.; Grbčić, P.; Topić, F.; Cetina, M.; Rissanen, K.; Pavelić, S.K.; Vianello, R.; Racané, L. Amidino substituted 2-aminophenols: Biologically important building blocks for the amidino-functionalization of 2-substituted benzoxazoles. Org. Biomol. Chem. 2021. [CrossRef] [PubMed]

60. Toma, M.; Božičević, L.; Lapić, J.; Đaković, S.; Šakić, D.; Tandarić, T.; Vianello, R.; Vrček, V. Transacylation in Ferrocenoyl-Purines. NMR and Computational Study of the Isomerization Mechanism. J. Org. Chem. 2019, 84, 12471. [CrossRef]

61. Cindrić, M.; Sović, I.; Mioč, M.; Hok, L.; Boček, I.; Roškarić, P.; Butković, K.; Martin-Kleiner, I.; Starčević, K.; Vianello, R.; et al. Experimental and Computational Study of the Antioxidative Potential of Novel Nitro and Amino Substituted Benzimidazole/Benzothiazole-2-Carboxamides with Antiproliferative Activity. Antioxidants 2019, 8, 477. [CrossRef]

62. Juraj, N.P.; Miletić, G.I.; Perić, B.; Popović, Z.; Smrečki, N.; Vianello, R.; Kirin, S.I. Stereochemistry of Hexacoordinated Zn(II), $\mathrm{Cu}(\mathrm{II}), \mathrm{Ni}(\mathrm{II})$, and $\mathrm{Co}(\mathrm{II})$ Complexes with Iminodiacetamide Ligands. Inorg. Chem. 2019, 58, 16445-16457. [CrossRef]

63. Juraj, N.P.; Krklec, M.; Novosel, T.; Perić, B.; Vianello, R.; Raić-Malić, S.; Kirin, S.I. Copper(II) and Zinc(II) Complexes of Monoand Bis-1,2,3-triazole substituted Heterocyclic Ligands. Dalton Transact. 2020, 49, 9002. [CrossRef] [PubMed]

64. Melekhova, A.A.; Smirnov, A.S.; Novikov, A.S.; Panikorovskii, T.L.; Bokach, N.A.; Yu, V. Kukushkin, Copper(I)-Catalyzed 1,3-Dipolar Cycloaddition of Ketonitrones to Dialkylcyanamides: A Step toward Sustainable Generation of 2,3-Dihydro-1,2,4oxadiazoles. ACS Omega 2017, 2, 1380-1391. [CrossRef] [PubMed]

65. Bolotin, D.S.; Demakova, M.Y.; Novikov, A.S.; Avdontceva, M.S.; Kuznetsov, M.L.; Bokach, N.A.; Yu, V. Kukushkin, Bifunctional Reactivity of Amidoximes Observed upon Nucleophilic Addition to Metal-Activated Nitriles. Inorg. Chem. 2015, 54 , 4039. [CrossRef] [PubMed]

66. Tandarić, T.; Vianello, R. Computational Insight into the Mechanism of the Irreversible Inhibition of Monoamine Oxidase Enzymes by the Antiparkinsonian Propargylamine Inhibitors Rasagiline and Selegiline. ACS Chem. Neurosci. 2019, 10, 3532-3542. [CrossRef] [PubMed]

67. Maršavelski, A.; Vianello, R. What a difference a methyl group makes-The selectivity of monoamine oxidase B towards histamine and N-methylhistamine. Chem. Eur. J. 2017, 23, 2915-2925. [CrossRef]

68. Foster, J.P.; Weinhold, F. Natural hybrid orbitals. J. Am. Chem. Soc. 1980, 102, 7211-7218. [CrossRef]

69. Frisch, M.J.; Trucks, G.W.; Schlegel, H.B.; Scuseria, G.E.; Robb, M.A.; Cheeseman, J.R.; Scalmani, G.; Barone, V.; Petersson, G.A.; Nakatsuji, H.; et al. Gaussian 16, Revision C.01; Gaussian, Inc.: Wallingford, CT, USA, 2016. 